\title{
Pore Network Analysis of Zone Model for Porous Media Drying
}

\author{
Yuan Yuejin, ${ }^{1,2}$ Zhao Zhe, ${ }^{1}$ Nie Junnan, ${ }^{1}$ and Xu Yingying ${ }^{1}$ \\ ${ }^{1}$ School of Mechanical and Electrical Engineering, Shaanxi University of Science and Technology, Xian, Shaanxi 710021, China \\ ${ }^{2}$ State Key Laboratory of Multiphase Flow in Power Engineering, Xian Jiaotong University, Xi'an, Shaanxi 710049, China
}

Correspondence should be addressed to Yuan Yuejin; yyjyuan1@163.com

Received 24 February 2014; Accepted 18 April 2014; Published 18 May 2014

Academic Editor: Zhijun Zhang

Copyright (C) 2014 Yuan Yuejin et al. This is an open access article distributed under the Creative Commons Attribution License, which permits unrestricted use, distribution, and reproduction in any medium, provided the original work is properly cited.

\begin{abstract}
In view of the fact that the zone model for porous media drying cannot disclose the mechanism of liquid phase distribution effectively, a pore network model for the slow isothermal drying process of porous media was developed by applying the theories of pore network drying and transport-process, which fused the physical parameters of porous media, such as porosity, pore mean diameter, and pore size distribution into the model parameters, and a sand bed drying experiment was conducted to verify the validity of this model. The experiment and simulation results indicate that the pore network model could explain the slow isothermal drying process of porous media well. The pore size distributions of porous media have a great effect on the liquid phase distribution of the drying process. The dual-zone model is suitable for the porous media whose pore size distribution obeys Gaussian distribution, while the three-zone model is suitable for the porous media whose pore size distribution obeys the lognormal distribution when the drying analysis of porous media is conducted.
\end{abstract}

\section{Introduction}

In general, the drying process of porous media can be divided into three periods: initial drying period, constant drying rate period, and falling drying rate period. When the moisture movement within porous media can no longer maintain the material surface saturated with liquid, the drying rate starts to decrease and the falling drying rate period begins. Currently, the zone model for porous media drying is often applying to the character analysis of the falling drying rate period [1]. In 1929 , Sherwood reported that there was an evaporation front interface during the falling drying rate period, which divided the drying material into two parts of different property: "dry zone" and "wet zone," and this was called the dual-zone model (Figure 1(a)). In the dry zone moisture is transferred in the form of vapour only, while in the wet zone liquid moisture will be transferred $[2,3]$. It is a great advance that the drying material is divided into two zones of different property by the dual-zone model in the process of the drying study. However, a large number of experimental studies have shown that sometimes there was not an obvious "evaporation front" interface inside the porous media during the falling drying rate period [4]. In 1932, Luikov and Kolesnikov proposed the three-zone model (Figure 1(b)), based on the study of the dual-zone model, and thought that the evaporation process of porous media drying took place in some region called the evaporation zone. Then, in a material subjected to drying, in general three zones can be distinguished (cf. Figure 1(b)): "dry zone," "evaporation zone," and "wet zone." During the constant drying rate period the wet zone fills the whole material and evaporation process takes place on the surface of the drying material. The evaporation and wet zones appear subsequently during the falling drying rate period. Both of the vapour and liquid moisture transfer mechanisms occur in the evaporation zone $[2,3]$.

From the above description, it can be seen that the zone model for porous media drying comes from the summarization of a large number of phenomenal observations and experimental researches and describes the liquid phase distribution during the process of porous media drying. But it cannot explain the internal mechanism of the "zone" phenomenon distinctly. Namely, which of the drying factors affects the liquid phase distribution during the process of porous media drying? It makes sometimes the "dual zones" appear clearly and at other times the "three zones" be much more consistent with the actual situation. Therefore, a pore 


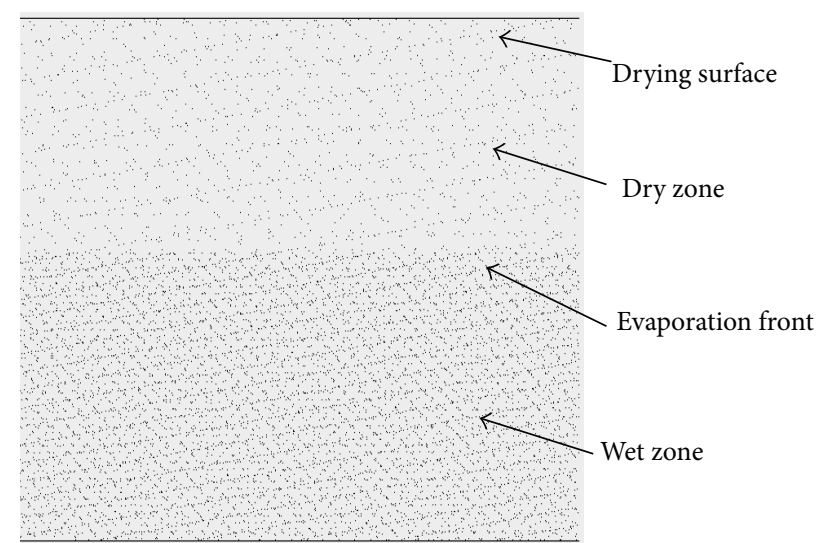

(a) Dual-zone model

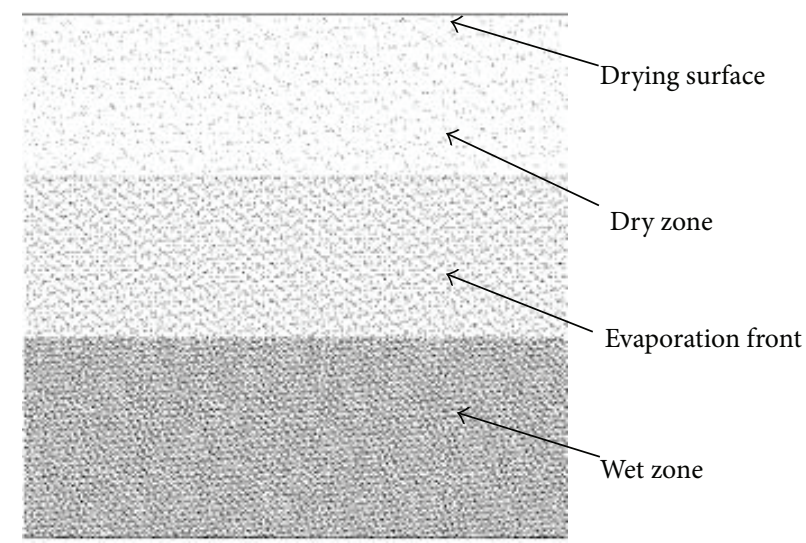

(b) Three-zone model

FIGURE 1: Sketch of zone models.

network model for the slow isothermal drying process of porous media would be developed in this paper by applying the theories of pore network drying and transport-process, which fused the physical parameters of porous media, such as porosity, pore mean diameter, and pore size distribution into the model parameters, and then the mechanism analysis of liquid phase distribution during the process of porous media drying was conducted.

The pore network method was introduced to the study of porous body drying by Daian, Nowicki, and others in the early 1990s, which was later developed by Prat and Yortsos. Finally, the pore network drying theory came into being [5-13], which was a method based on the discrete medium assumption. This theory assumed that the moisture transfer has great superiority in the pore space of porous media, that the node (pore) and throat are applied to describe the topological structure inside the porous media, and that the mass transfer in porous media is studied in the pore scale. Generally, the constructional procedure of the pore network physical model for porous media is shown in Figure 2, which includes four key steps: factual structure, distilled grids, regularized grids, and physical model. The model is mainly composed of two parts: pore-throat-pore network and solid skeleton $[5,14-16]$.

\section{Experimental Materials and Method}

In order to obtain the drying characteristics (such as liquid phase distributions inside a wet material and drying kinetics) in an isothermal slow drying process of real porous media and to verify the validity of the simulation results, a sand bed, which is representative of natural porous media, was chosen as the object of the drying simulation. The sand bed (Figure 3(a)) was composed of one packing ring and two layers of organic glass plate, and a drying container with the rectangular cavity of $3 \mathrm{~mm}$ thick was formed. When the experiment was going on, the prepared sand and alcohol were put into the drying container of sand bed. The density of the alcohol was $0.789 \mathrm{~g} / \mathrm{cm}^{3}$ and the room temperature was $293 \mathrm{~K}$. The sand bed was placed flatly on the electronic balance in order to obtain the drying curve of sand bed during the isothermal slow drying process. The digital camera was fixed above the sand bed, which took photos intermittently, in order to obtain the drying phase distribution.

Generally, the parameters for describing the structure characteristics of sand bed included the porosity $(P)$, pore size distribution $(f)$, pore mean diameter $\left(d_{m}\right)$, and the side length $(L)$. The pore network physical model of the sand bed was constructed (Figures 3(b) and 3(c)) by applying the above constructional procedure, and the mass transfer inside the sand bed was studied in the pore scale, and the scope of pore size was about $10^{-5} \sim 10^{-3} \mathrm{~m}$. The pore (node) was spherical, the throat was cylindrical, and the diameter of pores and throats followed certain probability distributions. A two-dimension pore network physical model could be described by the parameters of space distribution coefficient $(\beta)$, distance between two nodes $(a)$, pore size distribution $(F)$, and the number of model scale $(m)$ [5].

The relation between the structure parameter of sand bed and pore network physical model can be obtained by the analysis and computation. The distance between two nodes (a) is

$$
a=\frac{\sqrt{\pi} d_{m}}{2 \sqrt{P}} \approx 0.8862 \frac{d_{m}}{\sqrt{P}} .
$$

The pore size distribution $(F)$ of physical model is equal to the pore size distribution $(f)$ of sand bed; namely,

$$
F=f \text {. }
$$

The space distribution coefficient $(\beta)$ is

$$
\beta=1-\frac{\sqrt{P}}{0.8862} .
$$

The number of model scale $(m)$ is

$$
m=\operatorname{int}\left(1.1284 \frac{L \sqrt{P}}{d_{m}}\right),
$$

where int is the integral function. 


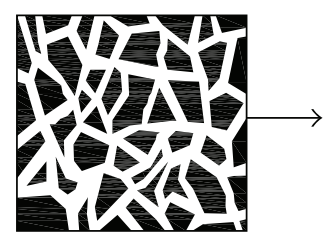

(a) Actual structure

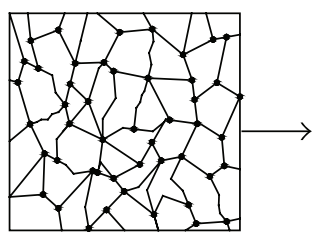

(b) Distilled grids

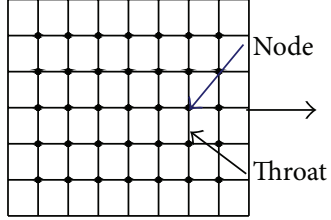

(c) Regularized grid

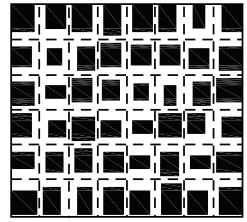

(d) Physical model

FIGURE 2: Construction of pore network physical model.

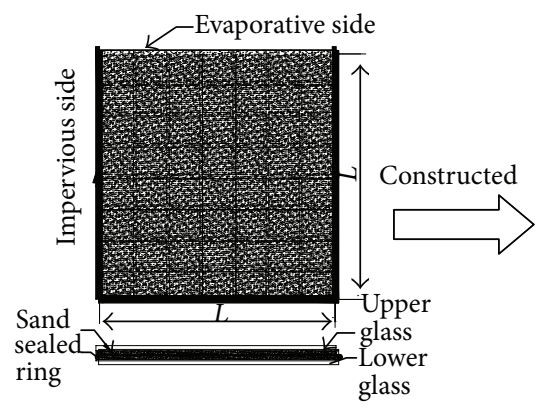

(a)

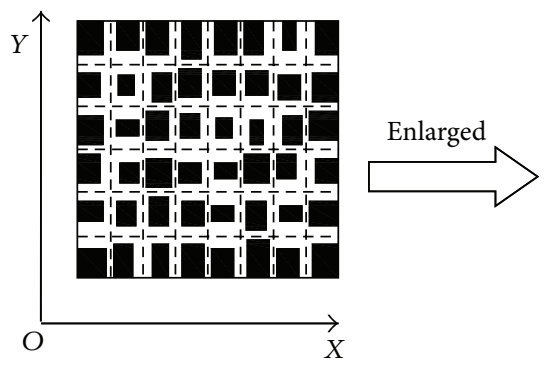

(b)

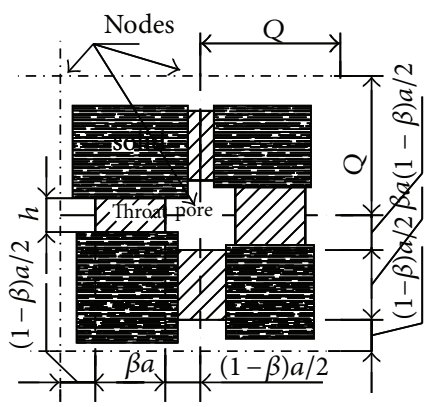

(c)

FIgURE 3: Sand bed (a), pore network physical model (b), and enlarged pore network (c).

\section{Pore Network Mathematical Model}

In this paper, we assumed that all the moisture was contained in the pore space. The following considerations are made in the "pore-throat" space network system model: (1) all the pores and throats are filled with liquid (alcohol) in the initial drying state; (2) convective mass transfer can be neglected, and diffusion mass transfer plays the leading role; (3) during the drying process, the sand bed was kept horizontal, neglecting the gravity effect for moisture transfer; and (4) the Kairvin effect and shrinkage during drying were neglected.

3.1. Mass Transfer Equation. Then, in the pore-throat space system of a physical model, for any vapor phase region, the equation below can be obtained by the law of conservation of mass:

$$
\frac{\partial m_{v}}{\partial t}=\nabla\left(k_{v} \nabla p_{v}\right)+S_{m v}
$$

where $m_{v}$ is the mass of vapor in the vapor phase region $(\mathrm{kg})$, $k_{v}$ is the effective diffusion coefficient of vapor $\left(\mathrm{m}^{3} / \mathrm{s}\right), p_{v}$ is the vapor pressure (pa), and $S_{m v}$ is the source item, that is, the evaporation rate of moisture on the "liquid-vapor" interface $(\mathrm{kg} / \mathrm{s})$.

During the drying process, the liquid phase flow caused by capillary force shows a saltation because of Haines jump [14]. Therefore, it is described by the drying simulating algorithm in the next paragraphs, and only the evaporating effect is taken into account now. In the "pore-throat" space system model, for any liquid phase region, the equation below can be obtained by the law of conservation of mass:

$$
\frac{\partial m_{l}}{\partial t}=-S_{m l}
$$

where $m_{l}$ is the mass of the liquid phase in the region $(\mathrm{kg})$ and $S_{m l}$ is the source item, that is, the evaporation rate of moisture on the "liquid-vapor" interface ( $\mathrm{kg} / \mathrm{s})$. When (5) and (6) are applied to the same region, the mass decrement of liquid phase caused by evaporation is just equal to the vapor mass addition of the vapor phase caused by evaporation; namely, $S_{m l}=S_{m v}$.

The mass transfer of liquid evaporation in certain pore $(i, j)$ of pore network was shown in Figure 4 . The liquid phase is a single-component phase, namely, wetting phase, while the vapor phase is binary mixture phase that is composed of vapor component and air component. When the system keeps constant temperature, the equilibrium concentration of vapor component on the interface is a constant. The equation of vapor flow rate on liquid-vapor interface can be obtained by Fick's law of diffusion:

$$
S_{m}=\frac{\pi d^{2} h M\left(C_{\mathrm{eq}}-C_{i, j}\right)}{2(1+\beta) a},
$$

where $d$ is the throat diameter (m), $h$ is the mass transfer coefficient $\left(\mathrm{m}^{2} / \mathrm{s}\right), M$ is the component molar mass $(\mathrm{g} / \mathrm{mol})$, $C_{\mathrm{eq}}$ is the equilibrium concentration of vapor component on the interface $\left(\mathrm{mol} / \mathrm{m}^{3}\right), C_{i, j}$ is the concentration of vapor 


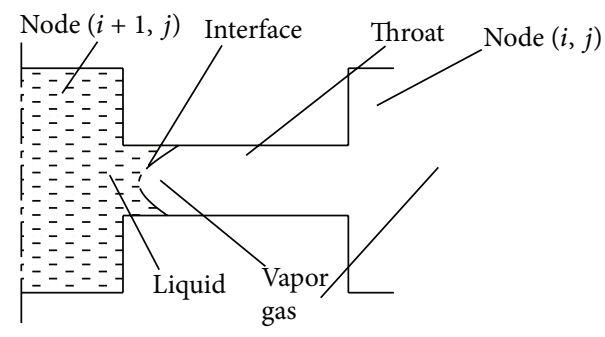

FIGURE 4: Moisture evaporation in pore $(i, j)$.

component in the pore $(i, j)\left(\mathrm{mol} / \mathrm{m}^{3}\right), \beta$ is the space distribution coefficient, and $a$ is the distance between two nodes $(m)$.

3.2. Simulation Algorithm of Drying. With the above equations (5), (6), and (7) and the proper initial and boundary conditions, the solution of a model of the two-dimensional pore network problem can be achieved. The steps of the computer modeling algorithm for drying can be summarized as follows.

Step 1, label every liquid cluster in the network (also called TC, just as (1), (2), and (3) shown in Figure 5). Step 2 , calculate the total evaporation flux of all the gas-liquid interfaces for every liquid cluster. For instance, in Figure 5, the total evaporation flux of the liquid cluster (1) is just the sum of evaporation flux of its eight throats at the gasliquid interface. Step 3, identify the throat of the lowest capillary pressure located at the frontier (gas-liquid interface) for each liquid cluster. Step 4, calculate the drying time of the total evaporation flux of every liquid cluster obtained in Step 2 and assigned to the throat identified in Step 3. Step 5, choose the throat which is the first to finish drying among the throats obtained in Step 4 as the finish-drying throat in this modeling periodicity, including its connected nodes. Meanwhile, calculate the evaporation flux of the throat having the lowest capillary pressure of other liquid clusters during this period, deducting the liquid evaporated from the corresponding throat. Step 6, update the liquid phase distribution within the network, and repeat the abovedescribed procedure until the model finishes drying entirely.

3.3. Initial and Boundary Conditions. The initial moisture content ratio is 1.0 for the simulation. The boundary conditions for the drying model are identical with the descriptions in the experiment section.

\section{Computer Simulations}

The programming tool Visual $\mathrm{C}++$ and MATLAB were applied to develop the modeling program in this paper. The programs generated the physical model of the twodimensional pore network based on the structural parameter of the material, and then such programs were performed according to the simulation algorithm of drying. In this course, (5)-(7) needed to be solved. The method of finite

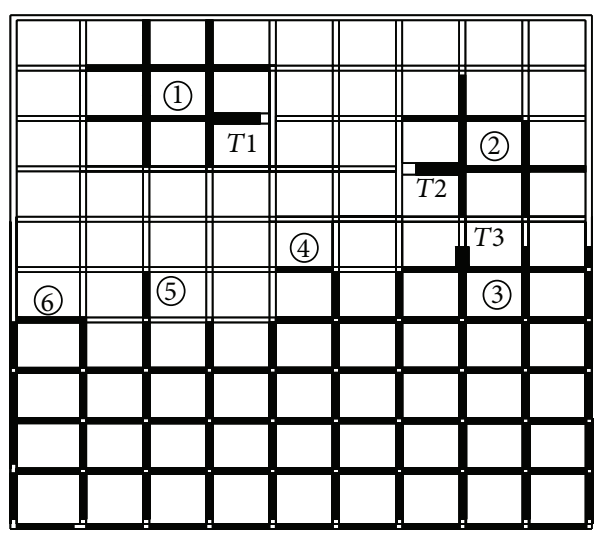

FIGURE 5: Liquid phase distribution of pore network drying.

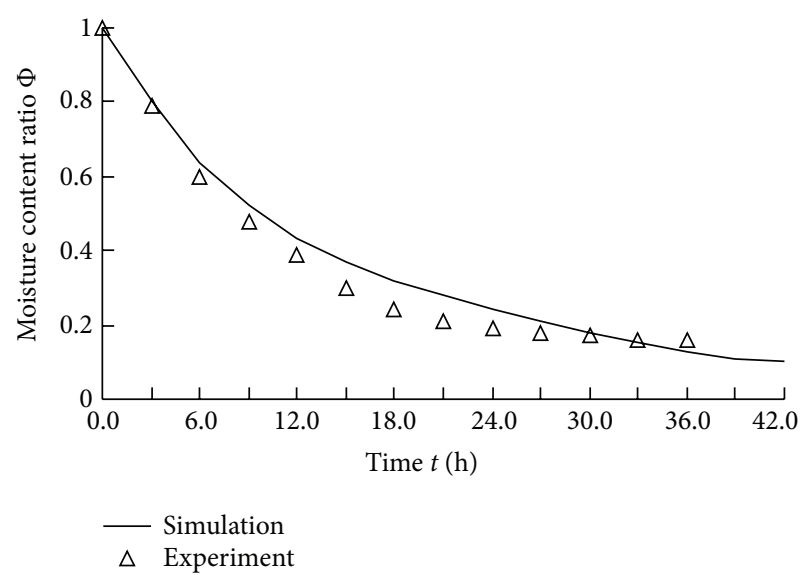

FIgURE 6: Drying curves comparison of experiment and simulation.

difference was used to disperse the equation set. The main parameters needed in the simulation are listed in Table 1.

\section{Results Analysis and Discussion}

\subsection{Comparison between Simulation and Experiment}

5.1.1. Drying Curves. It can be seen in Figure 6 that the moisture content ratio in the sand bed declined rapidly in the initial stages of drying. However, at the end of the drying, after about $24 \mathrm{~h}$, the drying curve was flattened out, which indicated that the drying speed declined and the sand bed was to reach equilibrium moisture content. The trend of the model-predicted drying curve agrees with the experimental curve and the values differ by no more than $11.2 \%$. This indicates that the model in this work can simulate the isothermal slow drying process of sand bed effectively.

5.1.2. Liquid Phase Distributions. It can be concluded from Figure 7 that there is a good agreement between the experiment and simulation liquid phase distributions, and this just corresponds with the above analysis of drying curves. 


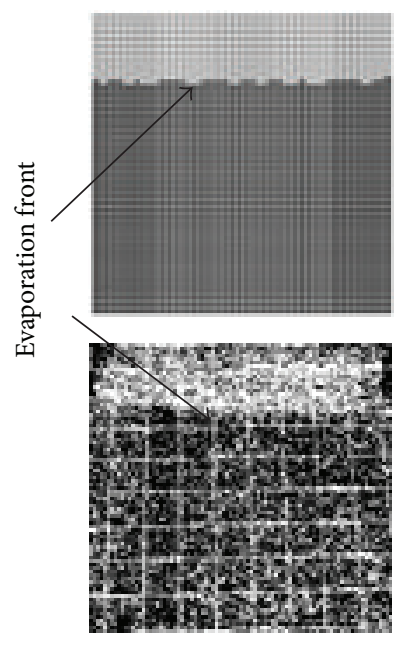

(I) $\Phi=83.9 \%$

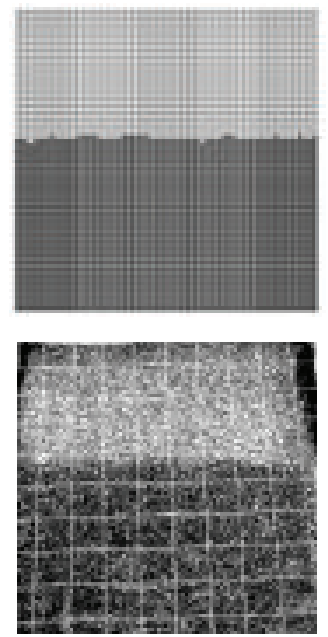

(II) $\Phi=55.2 \%$

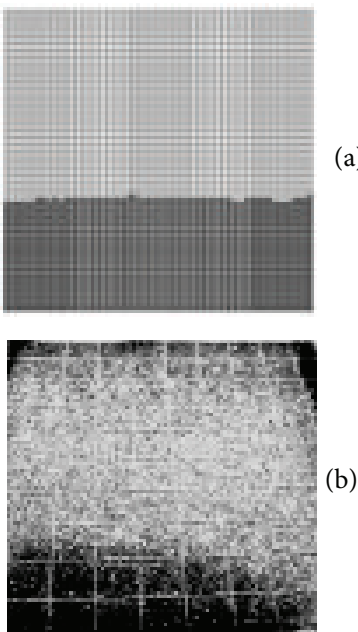

(III) $\Phi=26.7 \%$

FIGURE 7: Liquid phase distributions comparison of simulation (a) and experiment (b).
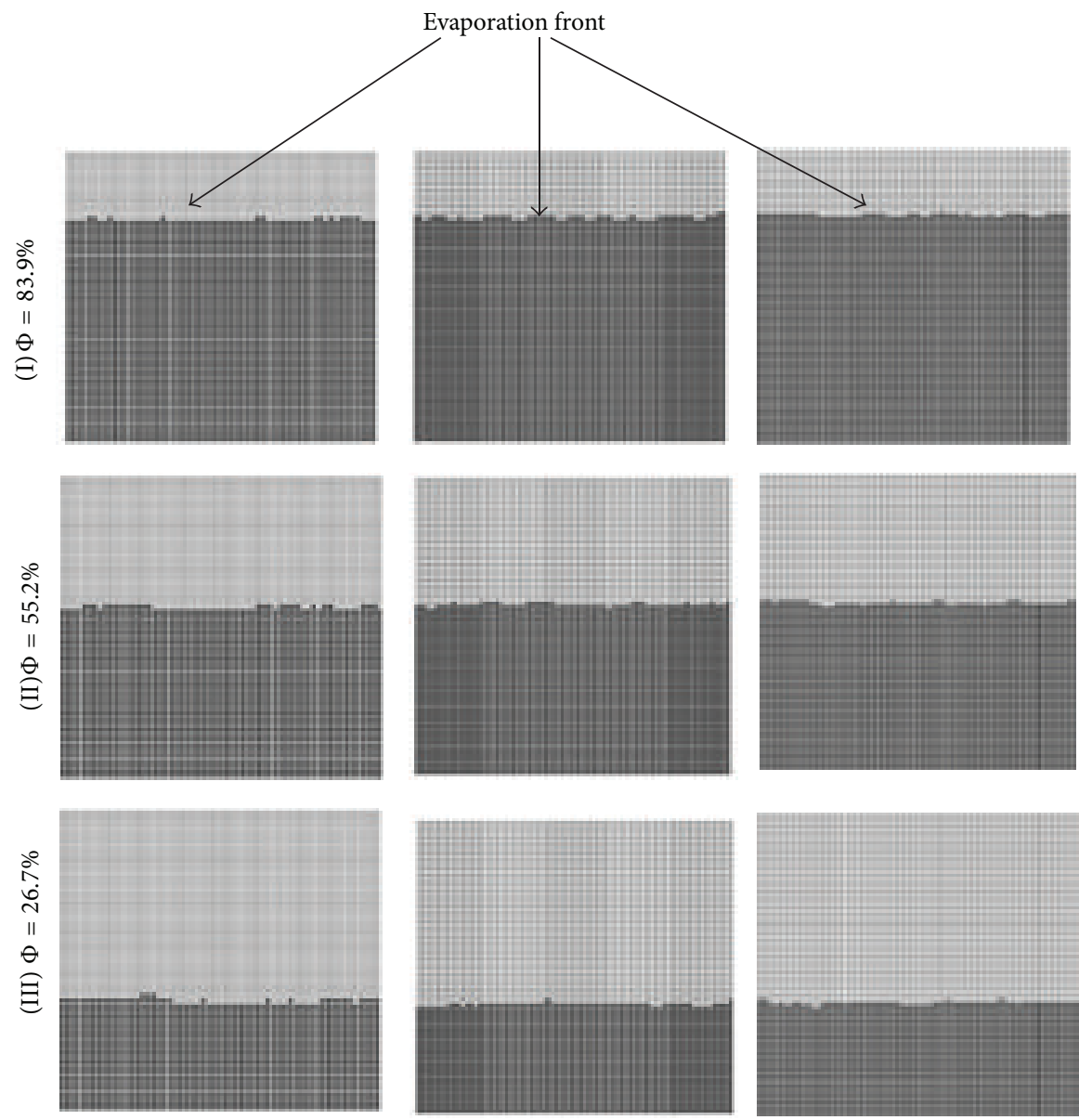

(a) $\beta=0.1708$

(b) $\beta=0.3044$

(c) $\beta=0.4707$

FIGURE 8: Simulated liquid phase distribution for different space distribution coefficients. 

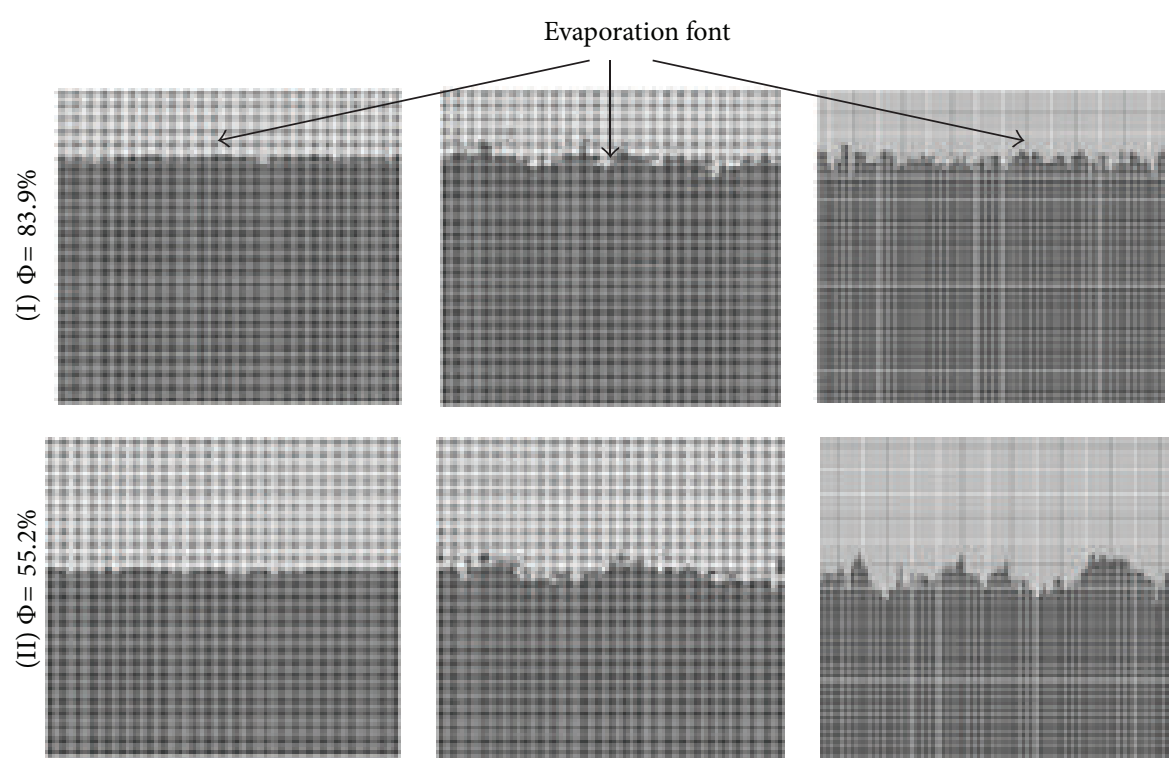

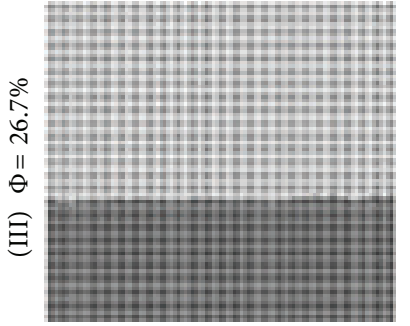

(a) Gaussian distribution

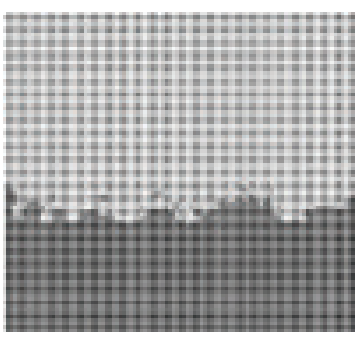

(b) Lognormal distribution

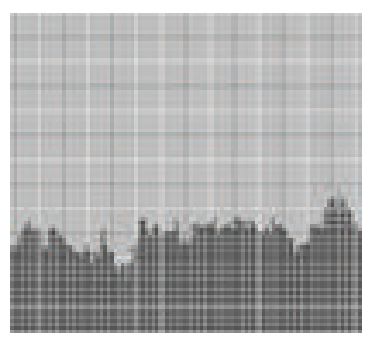

(c) Mixed distribution

FIGURE 9: Simulated liquid phase distribution for different pore size distributions.
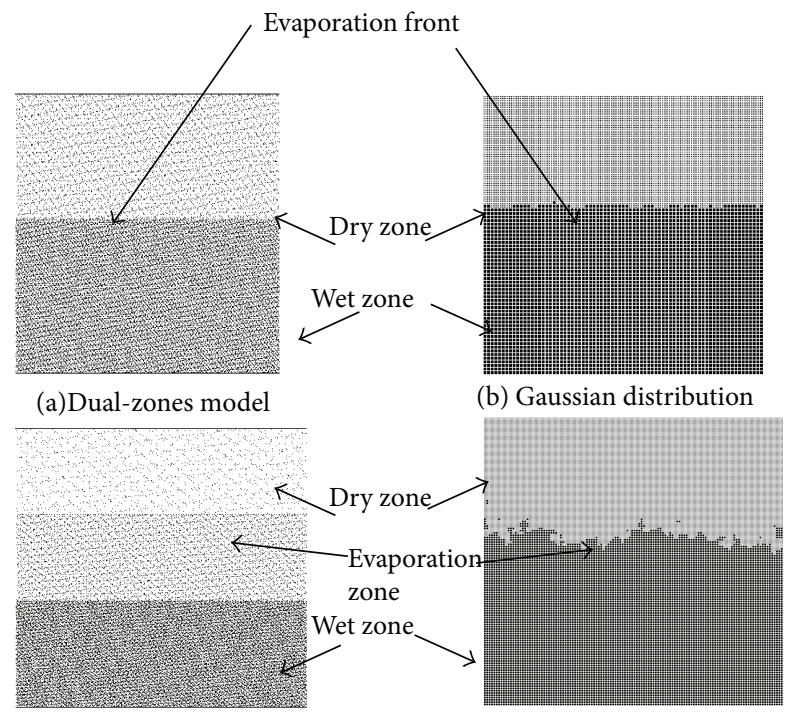

(c) Three-zones model

(d) Lognormal distribution

FIGURE 10: Comparison of zone model and simulation. 
TABLE 1: The main parameters during simulation.

\begin{tabular}{|c|c|c|c|}
\hline $\begin{array}{l}\text { Mass transfer coefficient } \\
\qquad\left(h / \mathrm{m}^{2} \cdot \mathrm{s}^{-1}\right)\end{array}$ & $\begin{array}{l}\text { Alcohol molar mass } \\
\qquad\left(\mathrm{M} / \mathrm{g} \cdot \mathrm{mol}^{-1}\right)\end{array}$ & $\begin{array}{l}\text { Alcohol equilibrium concentration } \\
\qquad\left(c_{\mathrm{eq}} / \mathrm{mol} \cdot \mathrm{m}^{-3}\right)\end{array}$ & $\begin{array}{l}\text { Alcohol density } \\
\left(\rho_{w} / \mathrm{g} \cdot \mathrm{mm}^{-3}\right)\end{array}$ \\
\hline $1.154 \times 10^{-4}$ & 46.063 & 2.423 & $0.789 \times 10^{-3}$ \\
\hline $\begin{array}{l}\text { Space distribution coefficient } \\
\qquad(\beta /-)\end{array}$ & $\begin{array}{l}\text { Distance between two nodes } \\
\qquad(a / \mathrm{mm})\end{array}$ & $\begin{array}{l}\text { Pore size distribution } \\
\qquad(F / \mathrm{mm})\end{array}$ & $\begin{array}{l}\text { Number of model } \\
\text { scale } \\
(m /-)\end{array}$ \\
\hline 0.3044 & 1.2858 & $\begin{array}{c}\text { Gaussian distribution } \\
\mathrm{N}\left(0.8944,0.1495^{2}\right)\end{array}$ & 77 \\
\hline
\end{tabular}

\subsection{Pore Network Simulation Analysis of Zone Model}

\subsubsection{Effect of Space Distribution Coefficient on Liquid Phase} Distribution. Drying simulations for different space distribution coefficients $(\beta)$ of $0.1708,0.3044$, and 0.4707 were carried out, all other unstated parameters applied were the same as the experimental parameters, and the liquid phase distribution of each was obtained (see Figure 8). From Figure 8, it is concluded that the space distribution coefficient $(\beta)$ has little significant influence on the liquid phase distribution of porous media during the drying process. The evaporation front interface almost keeps a traditional line.

\subsubsection{Effect of Pore Size Distribution on Liquid Phase Distribu-} tion. Drying simulations for different pore size distributions $(F)$ of Gaussian distribution $\mathrm{N}\left(0.8944,0.1495^{2}\right)$, lognormal distribution $\mathrm{LN}(-1.201,1.101)$ and the mixed distribution were carried out, and the $X$ direction of the mixed distribution obeyed Gaussian distribution $\mathrm{N}\left(0.8944,0.1495^{2}\right)$ and $Y$ direction of the mixed distribution obeyed lognormal distribution $\mathrm{LN}(-1.201,1.101)$, all other unstated parameters applied were the same as the experimental parameters, and the liquid phase distribution of each was obtained (see Figure 9). It can be seen in Figure 9 that the pore size distribution $(F)$ has a significant impact on the liquid phase distribution of porous media during the drying process. When the pore size distribution of porous media obeyed Gaussian distribution, the evaporation front interface almost kept a traditional line. However, when the pore size distribution obeyed the lognormal distribution and mixed distribution, the evaporation front interface displayed an irregular curve, and the wet patch appeared in some places.

The comparison of liquid phase distributions between the zone model and the simulation is shown in Figure 10. It can be seen from Figure 10 that there was a good agreement between the dual-zone model and simulation liquid phase distributions when the pore size distribution obeyed Gaussian distribution $\mathrm{N}\left(0.8944,0.1495^{2}\right)$, and there was also a good agreement between the three-zone model and simulation liquid phase distributions when the pore size distribution obeyed the lognormal distribution $\operatorname{LN}(-1.201,1.101)$.

From the above analysis of the effect of structure parameters on liquid phase distributions during the drying process of porous media, we can know that the pore size distribution $(F)$ has a significant impact on the liquid phase distribution.
Then, during the drying analysis of porous media, the dualzone model is suitable for the porous media whose pore size distribution obeys Gaussian distribution, while the threezone model is suitable for the porous media whose pore size distribution obeys the lognormal distribution. It can be seen from Figure 7 that the dual-zone model is more accordant with the experiment material because the pore size distribution of the sand bed obeys Gaussian distribution in Table 1 .

\section{Conclusions}

The pore network model presented in this paper can describe the slow isothermal drying process of the sand bed, the superiority of which is that the physical parameters of porous media, such as porosity, pore mean diameter, and pore size distribution, can be fused into the model parameters. The trend of the simulated drying curve agrees with that of the experimentally obtained curve. This indicates that the model in this work is effective.

The simulation results indicate that the space distribution coefficient has little significant influence on the liquid phase distribution of porous media during the drying process, but the pore size distribution has a significant impact on the liquid phase distribution. When the pore size distribution of porous media obeyed Gaussian distribution, the evaporation front interface almost kept a traditional line, and the dualzone model is suitable for the drying analysis. However, when the pore size distribution obeyed the lognormal distribution and mixed distribution, the evaporation front interface displayed an irregular curve, the wet patch appeared in some places, and the three-zone model is suitable for the drying analysis.

\section{Conflict of Interests}

The authors declare that there is no conflict of interests regarding the publication of this paper.

\section{Acknowledgments}

This work was financially supported by the National Natural Science Foundation of China (no. 51276105), the Natural Science Foundation of Shaanxi Educational Committee (no. 
2013JK1016), and the Graduate Innovation Fund of Shaanxi University of Science and Technology.

\section{References}

[1] Y. K. Pan, X. Z. Wang, and X. D. Liu, Modern Drying Technology, Chemical Industry Press, Beijing, China, 2nd edition, 2007.

[2] M. Fortes and M. R. Okos, "Drying theories: their bases and limitations as applied to foods and grains," Advances in Drying, vol. 1, pp. 119-154, 1980.

[3] C. Strumillo and T. Kudra, Drying: Principles, Applications and Design, Gordon and Breanch Science Publishers, 1986.

[4] M. Prat, "Recent advances in pore-scale models for drying of porous media," Chemical Engineering Journal, vol. 86, no. 1-2, pp. 153-164, 2002.

[5] M. Prat, "Percolation model of drying under isothermal conditions in porous media," International Journal of Multiphase Flow, vol. 19, no. 4, pp. 691-704, 1993.

[6] J. B. Laurindo and M. Prat, "Numerical and experimental network study of evaporation in capillary porous media, drying rates," Chemical Engineering Science, vol. 53, no. 12, pp. 22572269, 1998.

[7] A. G. Yiotis, A. G. Boudouvis, A. K. Stubos, and Y. C. Yortsos, "A pore network model for drying processes in porous media," in Proceedings of the ASME International Mechanical Engineering Congress and Exposition, pp. 53-60, New York, NY, USA, November 2001.

[8] L. A. Segura and P. G. Toledo, "Pore-level modeling of isothermal drying of pore networks accounting for evaporation, viscous flow, and shrinking," Drying Technology, vol. 23, no. 911, pp. 2007-2019, 2005.

[9] M. Prat, "On the influence of pore shape, contact angle and film flows on drying of capillary porous media," International Journal of Heat and Mass Transfer, vol. 50, no. 7-8, pp. 14551468, 2007.

[10] V. K. Surasani, T. Metzger, and E. Tsotsas, "A Non-isothermal pore network drying model with gravity effect," Transport in Porous Media, vol. 80, no. 3, pp. 431-439, 2009.

[11] A. G. Yiotis, I. N. Tsimpanogiannis, and A. K. Stubos, "Fractal characteristics and scaling of the drying front in porous media: a pore network study," Drying Technology, vol. 28, no. 8, pp. 981990, 2010.

[12] F. A. Sanmartin, J. B. Laurindo, and L. A. Segura, "Pore-scale simulation of drying of a porous media saturated with a sucrose solution," Drying Technology, vol. 29, no. 8, pp. 873-887, 2011.

[13] M. R. Shaeri, S. Beyhaghi, and K. M. Pillai, "On applying an external-flow driven mass transfer boundary condition to simulate drying from a pore-network model," International Journal of Heat and Mass Transfer, vol. 57, no. 1, pp. 331-344, 2013.

[14] Z. Xiao, D. Yang, Y. Yuan, B. Yang, and X. Liu, "Fractal pore network simulation on the drying of porous media," Drying Technology, vol. 26, no. 6, pp. 651-665, 2008.

[15] J. Chang, Y. J. Yuan, D. Y. Yang, and X. D. Liu, "Pore network model and simulation of transport process for grain drying," Chemical Engineering and Technology, vol. 34, no. 7, pp. 10491056, 2011.

[16] X. Huang, T. Qi, Z. Wang, D. Yang, and X. Liu, "A moisture transmembrane transfer model for pore network simulation of plant materials drying," Drying Technology, vol. 30, no. 15, pp. 1742-1749, 2012. 


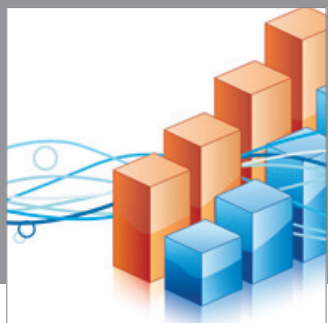

Advances in

Operations Research

mansans

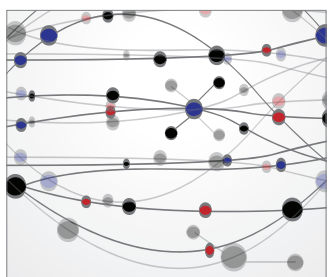

The Scientific World Journal
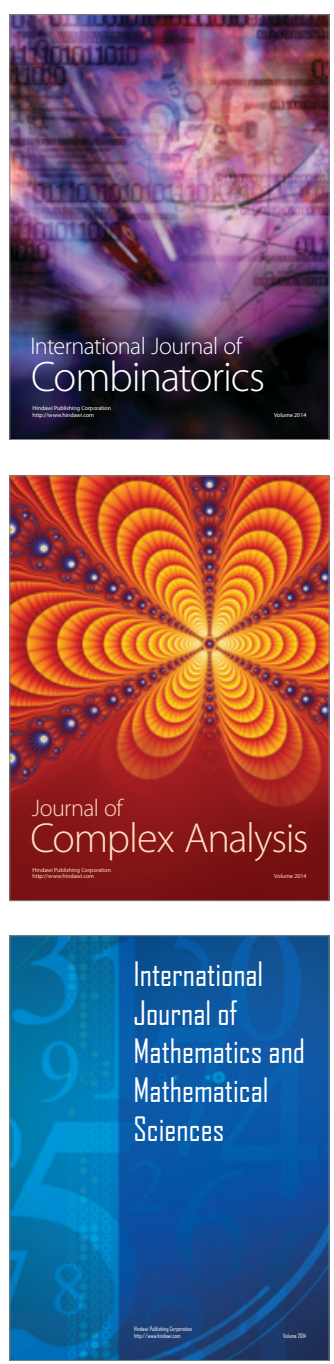
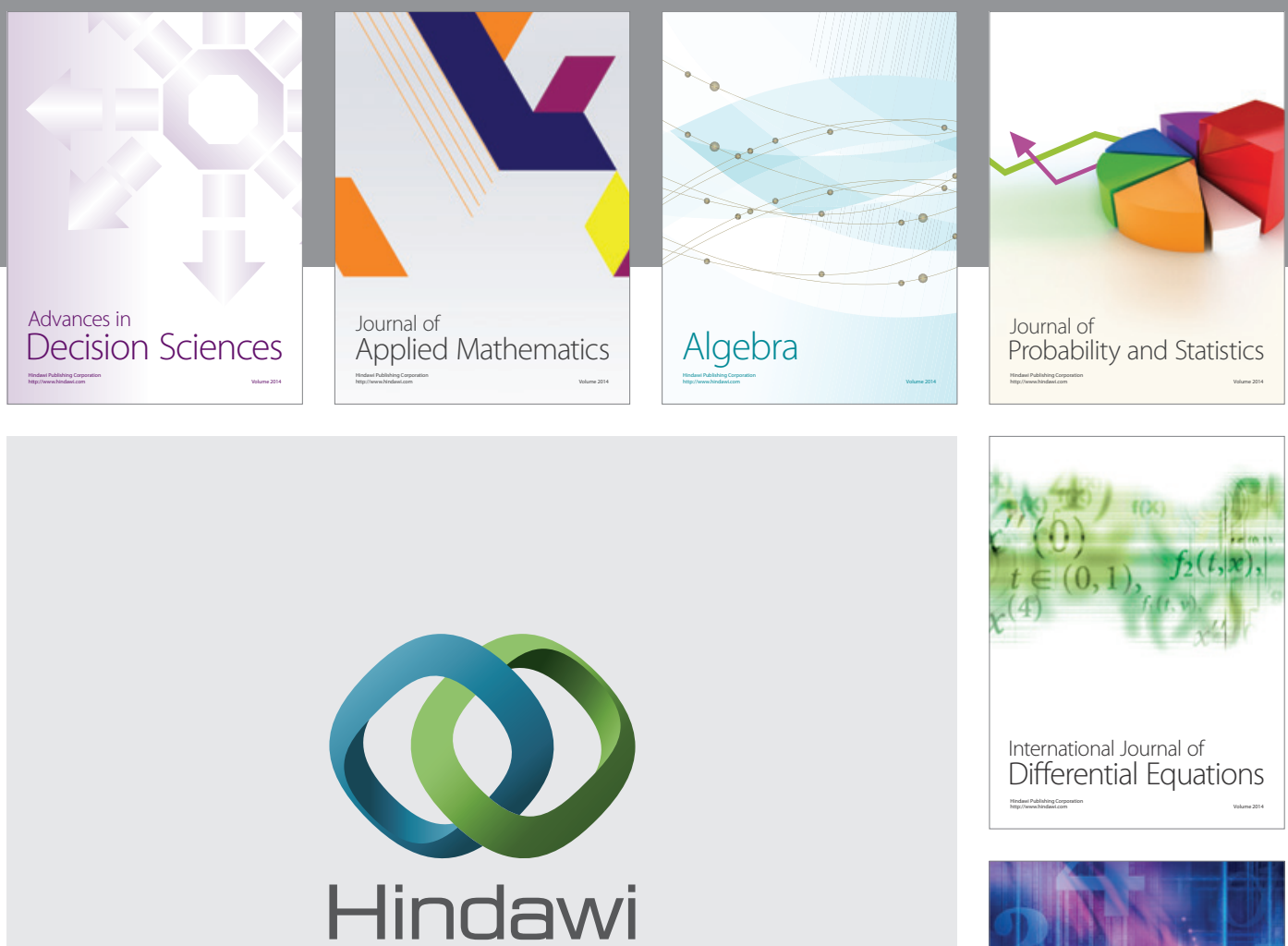

Submit your manuscripts at http://www.hindawi.com
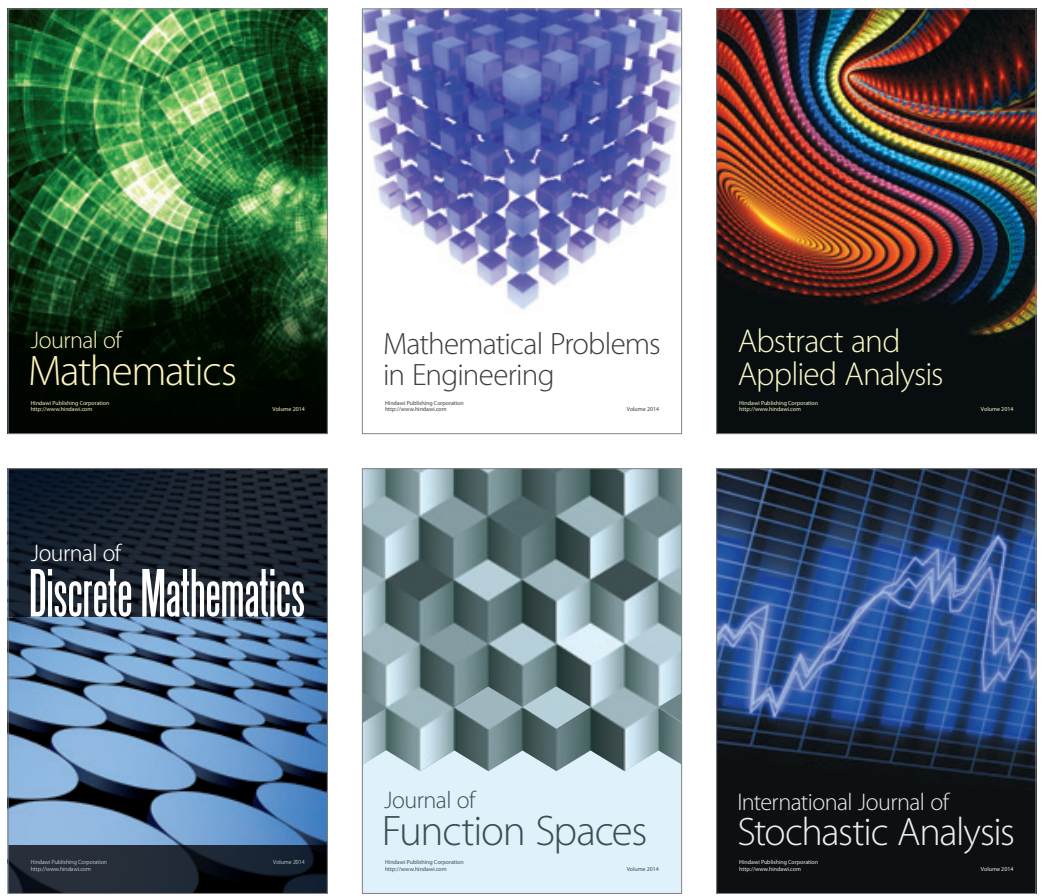

Journal of

Function Spaces

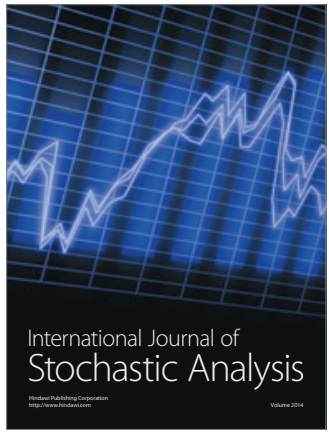

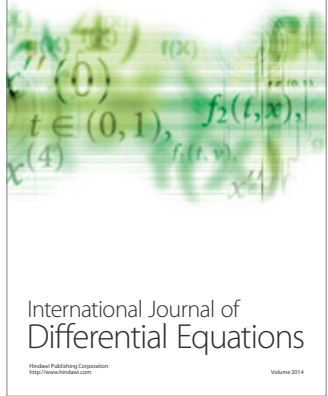
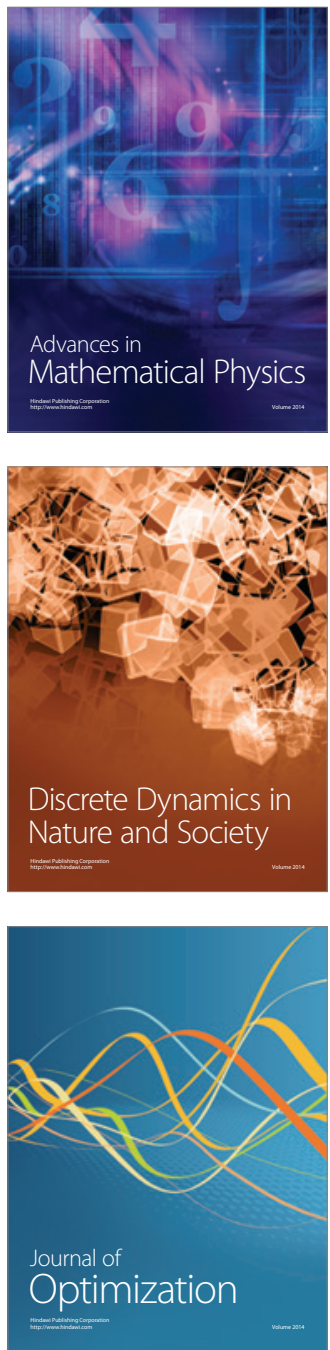